\title{
Exploring sparse connectivity in the motor system using multivariate autoregression analysis
}

Rafael Rodriguez-Rojas*1, Mayrim Vega-Hernandez², Agustín Lage ${ }^{2}$, Jose Sanchez ${ }^{2}$, Maylen Carballo ${ }^{1}$, Jorge Bosh ${ }^{2}$ and Pedro Valdes-Sosa ${ }^{2}$

Address: ${ }^{1}$ Brain Images Processing Group, International Center for Neurological Restoration, Havana, Cuba and ${ }^{2}$ Neurophysics Department, Cuban Neuroscience Center, Havana, Cuba

Email: Rafael Rodriguez-Rojas* - rafael.rguez@infomed.sld.cu

* Corresponding author

from Sixteenth Annual Computational Neuroscience Meeting: CNS*2007

Toronto, Canada. 7-12 July 2007

Published: 6 July 2007

BMC Neuroscience 2007, 8(Suppl 2):PI38 doi:I0.1 I86/147|-2202-8-S2-PI38

(c) 2007 Rodriguez-Rojas et al; licensee BioMed Central Ltd.

\section{Background}

Multivariate autoregressive (MAR) models can be used in the identification of causal relations from functional MRI time series. Connectivity information is extracted from large neural networks combining graphical modeling methods and Granger causality. The aim of this paper is to demonstrate the feasibility of working with the MAR models to identify functional circuits in the human motor system, and demonstrates their application to data of motor performance in patients with Parkinson's disease (PD).

\section{Methods}

In this work we incorporate a family of linear methods called penalized linear regression that were designed to deal with problems having a large set of variables (i.e.
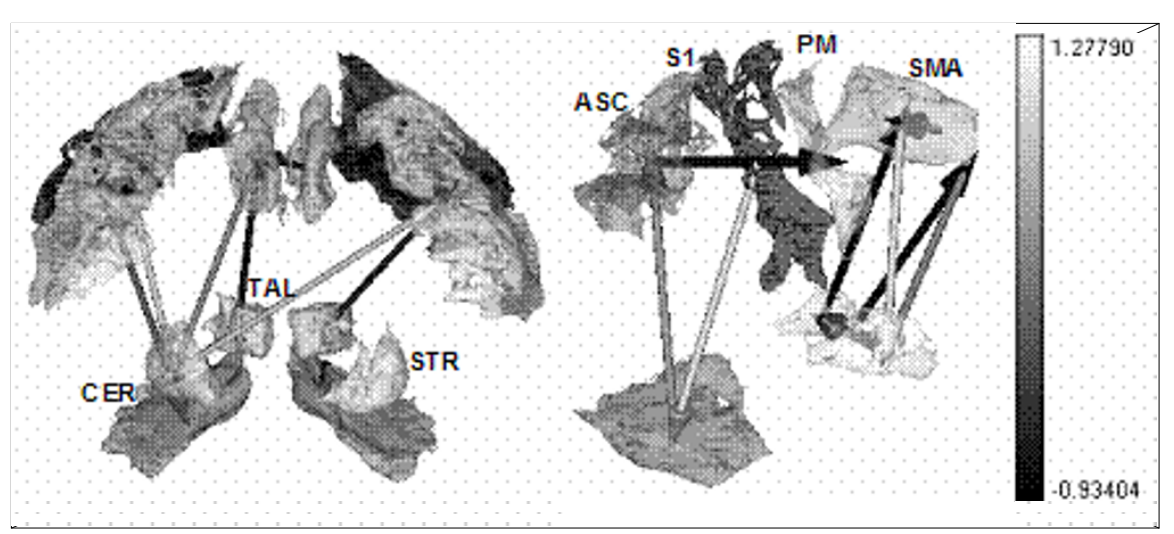

Figure I

Realistic rendering of effective connections in the motor system. Note involvement of areas related to motor performance. MI: Primary motor cortex, SI: Primary somatosensory cortex, PM: Premotor cortex, SMA: Supplementary motor area, ASC: Associative parietal cortex, STR: Striatum, TAL: Thalamus, CER: Cerebellum. 
Table I: Effects of L-Dopa treatment on strength of inter-regional path coefficients

\begin{tabular}{ccc}
\hline Connection & OFF Medication & ON Medication \\
\hline ASC - PRE & 0.035 & 0.789 \\
TAL - PM & 0.062 & 0.154 \\
TAL - SMA & 0.093 & 0.256 \\
STR - TAL & 0.018 & -0.386 \\
TAL - SMA & 0.093 & 0.256 \\
\hline
\end{tabular}

brain structures) and a relatively small set of observations (i.e. fMRI time points). One parkinsonian patient with early stage akinetic PD was studied by fMRI during the "drug-off" state and after reaches the "drug-on" state (table 1).

\section{Results}

The statistically most relevant connections from the connectivity matrix, in parkinsonian state, are summarized in the realistic rendering shown in Figure 1. These results indicate that the components of the basal ganglia-thalamus-cortical circuit were functionally connected to each other, but also functional connections in the cortico-cerebello-thalamo-cortical pathway are evidenced.

\section{Conclusion}

In opposition to widely spread methods for connectivity analysis, the proposed algorithm does not rely on preconditioned connections between regions from anatomical models. The penalized regression techniques expand the basic idea of ordinary least squares by means of the addition of new terms to the minimization equation. Our results support that MAR models form a valuable and feasible approach to study functional circuits in the human motor system, in normal and disease condition.
Publish with Bio Med Central and every scientist can read your work free of charge

"BioMed Central will be the most significant development for disseminating the results of biomedical research in our lifetime. " Sir Paul Nurse, Cancer Research UK

Your research papers will be:

- available free of charge to the entire biomedical community

- peer reviewed and published immediately upon acceptance

- cited in PubMed and archived on PubMed Central

- yours - you keep the copyright

Submit your manuscript here:

http://www.biomedcentral.com/info/publishing_adv.asp 